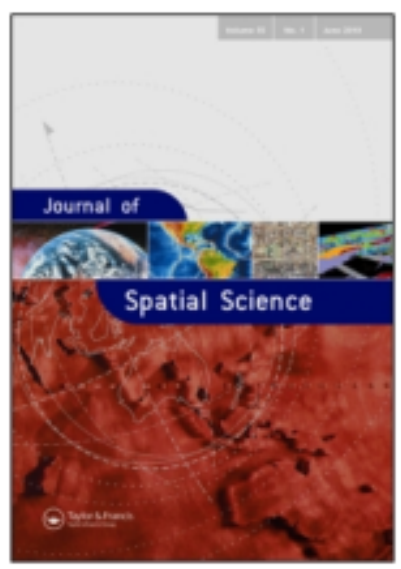

Double cross: geographic profiling of V-2 impact sites

\begin{tabular}{|r|l|}
\hline Journal: & Journal of Spatial Science \\
\hline Manuscript ID & TJSS-2019-0043.R1 \\
\hline Manuscript Type: & Research and Review Papers \\
\hline Keywords: & $\begin{array}{l}\text { double cross, Dirichlet process mixture model, Bayesian, spatial analysis, } \\
\text { V-2 }\end{array}$ \\
\hline
\end{tabular}

\title{
SCHOLARONE
}

Manuscripts 


\section{Double cross: Geographic profiling of V-2 impact sites}

Between September 1944 and March 1945, more than a thousand V-2 rockets struck Great Britain, causing 2,754 deaths-and 6,523 injuries.. Unlike the V-1, the V-2 could not be shot down, and M.I.5 responded with an ingenious scheme to mislead the Germans about the impact sites so they would shorten the range, missing Westminster and the docks. This is widely regarded as a success, with claims that the M.P.I. moved eastwards by two miles a week, ending outside London and saving 1,300 lives. Here, we use geographic profiling - a statistical technique originally developed to prioritise large-lists of suspects in cases of serial crime - to show that this deception had little or no effect. Our results suggest rockets aimed at a single target would form clusters of $30 \mathrm{~km}$ radius, swamping the claimed movement. Our study shows how geographic profiling may be applied to diverse data sets beyond criminology and epidemiology.

Keywords: double cross; M.I.5, rocket; spatial analysis, V-2 


\section{Introduction}

At $6.41 \mathrm{pm}$ on September $8^{\text {th }}, 1944$, the first V-2 to fall on Britain struck the west London suburb of Chiswick near the junction of Burlington Lane and Staveley Road, killing three people; 16 seconds later the second fell 16 miles away near Epping (Dungan 2005). Over the next six months, over a thousand rockets fell on Britain, around half of them in and around London, causing a total of 2,754 deaths and 6,523 injuries (Andrew 2012). Individual attacks could be devastating: one rocket which struck Hughes Mansions in Vallance Road in London's East End on March 27th 1945 (Figure 1) killed 134 people, while another that fell on Woolworths in New Cross on November $25^{\text {th }} 1944$ killed 160 people-(Figure 1).

With a maximum altitude of $88 \mathrm{~km}$ and a speed of up to $5,760 \mathrm{~km}$ hour ${ }^{-1}$, the V2 was essentially invulnerable to anti-aircraft fire and to attacks by fighter aircraft, both of which had been successful against the V-1 'flying bombs' (although there is an account of a V-2 being shot down by a Liberator (Johnson 1982), it is unclear whether this was an actual event or allied propaganda). In the absence of direct countermeasures, British intelligence instead adapted a scheme that they had already used in response to the V-1 flying bombs:

\footnotetext{
'The dilemma facing M.I.5 [Military Intelligence section 5; the UK's domestic counter-intelligence and security agency] was that the Germans were now telling their supposed London agents to report the times and places of flying bomb incidents in London. If, to preserve the security of possible future deceptions, we were to supply truthful information to the Germans, this would be aiding the enemy. If, on the other hand, we supplied false information, then this could be checked by German photographic reconnaissance, in which case the agents would be 'blown' and future deception plans ruined. [...]

It immediately occurred to me that photographic reconnaissance could only reveal the points of impact, and not the times. Moreover, I knew from previous
} 
experience that while agents could usually define the place of an incident fairly well, they were likely to be wrong in other details, even the times.

I had noticed that in the Peenemünde trials the bombs tended to fall short of the target, and now knew from the plot of bombs for the first 24 hours that the operational bombs were also tending to fall short, with the centre of gravity being in south-east London, near Dulwich. In a flash I saw that we might be able to keep the bombs falling short, which would mean fewer casualties in London as a whole, and at the same time avoid arousing any suspicions regarding the genuineness of the agents.

We could give correct points of impact for bombs that tended to have a longer range than usual, but couple these with times of bombs which in fact had fallen short. Thus, if the Germans attempted any correlation, they might be led to think that the bombs which they had reason to think might have fallen short were instead tending to fall in north-west London. Therefore, if they made any correction at all, it would be to reduce the average range.' (Jones 1978)

\section{JC Masterman, the chairman of the Double-Cross Committee (see below), tells a similar story in a document originally written as a report for M.I.5 in 1945 but published publically 27 years later (Masterman 1972):}

\footnotetext{
'Early in September the rocket attacks (V-2) started, and presented us with similar problems and similar opportunities to those connected with V-1. Consequently, our deception was also on similar lines. There was, however, a technical difference. In the flying bomb attacks location had been the important factor because it was doubtful whether the enemy could tie the times we gave them to particular shots; in the rocket attacks timings were vital because the enemy could calculate accurately the time of arrival of any shot, and link this up with any information which we gave him. It was therefore decided to give real incidents which would show an M.P.I. [mean point of impact] in Central London, but to give as the times for those incidents the times of shots falling some five to eight miles short. In this way over a period of some months we contrived to encourage the enemy steadily to diminish his range; thus in the four weeks from 20 January to 17 February 1945 the real M.P.I. moved eastward about two miles a week and ended well outside the boundary of London region.' (Masterman 1972)
} 
It is interesting to note in passing the discrepancy between Jones's account, which suggests that time was a factor in both the V-1 and V-2 deceptions, with Masterman's version, which highlights this as the key difference between the V-1 and V-2 deceptions.

Crucial to this deception was the Twenty Committee, which later became known as the Double-Cross Committee because of the representation of 20 in Roman numerals as XX. The Double-Cross Committee used Nazi agents in Britain to broadcast disinformation to the Germans in a way that would benefit the Allies, and it did so astonishingly effectively. Masterman (1972) claimed that M.I.5 effectively ran and controlled the German espionage system in Britain. Startlingly, it became clear after the war that all of the agents sent to Britain had either been captured or had given themselves up, with the possible exception of one who committed suicide (Masterman 1972, Macintyre 2012).

The two key double agents in the V-2 story were Tate and Rover. Tate (Wulf Schmidt, later known as Harry Williamson) parachuted into England in September 1940. However, he had been betrayed by a previously captured agent. The agent, Gösta Caroli, was a friend of Schmidt, and made Schmidt's protection a condition of his cooperation; Schmidt was told that Caroli had betrayed him and, furious, swapped sides (Macintyre 2012). Although none of Tate's reports on V-2 impacts seem to have survived in either British or German files, Masterman told a meeting of the Double Cross Committee on 18 January 1945 that the Germans were strongly influenced by Tate and Rover's reports on V-2 strikes. Tate, in fact, so completely deceived the Germans that one Abwehr official believed his reports about the plans for D-day could 'even decide the outcome of the war' (Masterman 1972; Jonason \& Olsson 2012). Rover was a Polish sailor who had been captured by the Nazis and used as forced 
labourer before being offered the opportunity to spy for the Germans. He arrived in Gibraltar and immediately confessed to the authorities, before being sent to England in 1944 to work as a double agent. However, the Germans failed to respond to his initial contacts and he was allowed to return to the Polish Navy. Shortly after this the Germans contacted him, and in his absence a British operator familiar with his technique as a wireless operator was successfully used as a substitute. This substitute then became ill and died, and a second substitute was found after a short interval, managing to explain the gap in transmissions by claiming he had been hit by a lorry during the blackout (Masterman 1972; Crowdy 2011).

There is good evidence that the V-1 and V-2 deception operations worked; according to Andrew (2012) the Security Service reported to Churchill that during January 1945 that 'TATE and ROVER have been successfully applying misleading information about the fall of V.1. and V.2., and there is some reason to believe that their messages are having an effect of the places where the missiles are falling'. The following monthly report concluded 'TATE and ROVER have continued to supply misleading information about the fall of V.2 and it is now possible to conclude with some certainty that the shift to the north-east of London of the mean point of impact of V.2 is due to reports from Special Agents' (Andrew 2012). Masterman (1972) cites a captured German map based on agents' reports that showed the M.P.I. in the Charing Cross area, and points out that this was exactly what British Intelligence wished the Germans to believe. Similarly, Jones (1978) refers to a captured map with a written comment addressing the discrepancy between data from the small number of $\mathrm{V}-1$ 's fitted with radio transmitters (the existence of these was unknown to M.I.5 at the time) which suggested that the bombs were tending to fall short, and data from the agents who claimed they were overshooting(Figure 2).. The comment states that the agents are 
particularly reliable, and that there must therefore be something wrong with the radio D/F method (Jones 1978). It is obviously impossible to put precise figures on the number of lives that might have been saved by this deception, but Andrew (2012) suggests 1,300 more dead and 10,000 more injured, in addition to the other consequences of additional impacts on the area between Westminster and the docks.

The problem with the claim that the mean point of impact moved eastward as a result of this deception is that the spatial mean is not a good metric to use, since it will be biased by bombs falling in other areas - for example, Norwich, Southend and Canvey Island. Here, we address this issue with a re-analysis of the data that uses geographic profiling to cluster the impacts, and then looks specifically at the cluster centred on London.

Geographic profiling was originally developed in criminology, where it is used to prioritise the large lists of suspects typical in investigations of serial crime (for example murder). In this context, the model uses the spatial locations of linked crimes to make inferences about the most likely locations of the offender's 'anchor point' usually a home or workplace, but sometimes a relative's home. It is routinely used by law enforcement agencies around the world (Rossmo 2000), and its success in this field has led in the last few years to its application to more varied datasets, notably in biology and epidemiology (Le Comber \& Stevenson 2012; Faulkner et al. 2016; Faulkner et al. 2018), where it can be used to find - for example - the sources of outbreaks of infectious disease (e.g., using the addresses of patients suffering from malaria to find the breeding sites of the mosquitoes that spread the malarial parasite) (Verity et al. 2014). It has also been applied to more esoteric cases such as Banksy artworks or instances of human-tiger conflict (Hauge et al. 2016; Struebig et al. 2018). This application to datasets that - unlike criminal investigations - may feature multiple 
sources, and where the number of sources is unknown, has gone hand-in-hand with the development of more rigorous Bayesian models, notably the Dirichlet Process Mixture (DPM) model introduced in Verity et al. (2014) and extended in Faulkner et al. (2016). Here, we use the DPM model to analyse the spatial locations of V-2 impacts on England during the second world war.Second World War. Specifically, we ask (1) whether there is any evidence of clustering of impact sites within London; (2) whether the M.P.I. of rockets striking London does indeed move eastwards, especially over the crucial period in January-February 1945.

\section{Methods}

\section{Data}

Datafor 1,115 V-2 strikes were obtained from https://www.wrsonline.co.uk, which details accounts of V-2 bomb locations and victims within Britain. The website provides a map of all V-2 strikes within Britain, compiled using official data from The Ministry of Defence's document AIR 20/4126 'Big Ben'. Source code was downloaded for this map in JSON format. Geographical strike site data were extracted and converted to CSV format using an online data converter (https://www.doogal.co.uk/BatchGeocoding.php). One strike site with incomplete geographical location data was excluded, leaving 1,115 data points detailing location (latitude and longitude) and date (day, month and year) of each strike site. 


\section{The Dirichlet Process Mixture model}

The Dirichlet process mixture model was introduced in Verity et al. (2014) and extended in Faulkner et al. (2016); crucially, it provides a mathematically robust way of estimating source locations from the spatial locations of the observations, even where the number of sources is unknown. The model breaks down the difficult problem of estimating the locations of multiple sources into two much simpler problems using a Gibbs sampler (Geman \& Geman 1984). First the model partitions the observations into clusters, with observations that are close together more likely derived from the same source. Second, the model estimates the locations of the sources, conditional on the clustering in the first step. The model repeats these steps many thousands of times using standard Bayesian Markov Chain Monte Carlo (MCMC) methods until it converges on the posterior distribution of interest (Verity et al. 2014; Faulkner et al. 2016). In this study, the locations of the estimated sources are considered analogous to the M.P.I. in Masterman (1972), with the important difference that this 'mean' is restricted to the impacts associated with the cluster in/around London and is therefore not biased by the inclusion of more distant impacts.

\section{Model implementation}

The DPM model described here was implemented in R (R Core Team 2015) using version 2.1.0 of the package Rgeoprofile introduced by Verity et al. (2014) and extended in Faulkner et al (2016); this package is available at https:/github.com/bobverity/Rgeoprofile. Model settings are explained in detail in Verity et al (2014). First, we ran the model on the full set of impact locations using the settings sigma_mean $=1$, sigma_var $=$ NULL, sigma_squared_shape $=2$, samples $=$ 100,000, chains $=10$, burnin $=1000$. These settings correspond to a very diffuse prior 


\section{Hitscore percentage}

The model's performance is assessed by the hitscore percentage. In a criminal investigation, the suspect site's hitscore is the proportion of the geoprofile that must be searched before that site is located; the lower the hit score, the higher priority the 'suspect'. In this instance, the hit score percentage can be thought of as analogous to the extent to which an area is targeted.

\section{Mean point of impact and median point of impact}

Starting from the first impacts on September $8^{\text {th }}$, 1944, we calculated rolling mean and median point of impact in daily periods of 14-day groups; that is, from September 8-21 1944, September 9-22, etc, until March 18-31, 1944. We also calculated mean point of impact in the same way, but restricting the analysis to strikes within London-(defined as all boroughs falling under the Greater London Authority; this largely corresponds to the London Civil Defence Region used in Evans and Delaney (2018)). Over the same windows, we also ran the Dirichlet Process Mixture model, as described above, extracting at each step the most likely position for the source of those points assigned to the cluster closest to London. If no 'source' was within $10 \mathrm{~km}$ of Tower Bridge (the actual target, according to Jones (1978)),,, although Williams (2013) suggests the first rockets were targeted at Southwark Fire Station, approximately $2 \mathrm{~km}$ away), no mean 
was calculated.

\section{Poisson analysis}

Following Clarke (1946), we divided the area into a 32 x 32 grid encompassing the strikes allocated to the London cluster by the DPM and compared the numbers of strikes per cell to those expected with a Poisson distribution, i.e. if the distribution of impacts is purely random.

\section{Results}

\section{Clustering within London}

Table 1 shows the observed and expected number of cells with zero to four strikes when the data are restricted to impacts allocated by the DPM to the cluster in and around London. This shows a significant departure for the numbers expected under a Poisson distribution (chi squared test: $\mathrm{X}^{2}=285.78, \mathrm{df}=4, \mathrm{p}<0.0001$ ).

\section{Geographic profiling}

Running the model with the complete list of impact locations yielded a fitted sigma value of $10.02 \mathrm{~km}$, which we rounded to $10 \mathrm{~km}$. Sigma represents the standard deviation (in $\mathrm{km}$ ) of the dispersal distribution around the source. A sigma value of $10 \mathrm{~km}$ therefore implies that $39 \%$ of the impacts events occur within $10 \mathrm{~km}$ from the source, $87 \%$ within $20 \mathrm{~km}$ and 99\% within $30 \mathrm{~km}$. Overall, the DPM model assigned 679 strikes to the central London cluster (note that this number does not correspond to the 
729 strikes in Table 1 that landed within the London Region, since not all of these were assigned to this cluster). This cluster had mean location $51.54060^{\circ}$ latitude, $0.05340516^{\circ}$ longitude, close to Plashet Park in the east end of London, approximately $10 \mathrm{~km}$ WSWENE of Tower Bridge. The mean inter-strike distance for the points assigned to this cluster was $16.91 \mathrm{~km}$, close to the mean distance between points in a bivariate normal distribution-with standard deviation equal to this fitted value of sigma, which is given by sigma $* \mathrm{pi}^{\wedge} 0.5$; in this case, $17.7 \mathrm{~km}$. Therefore, the mean distance between points is also consistent with a roughly bivariate normal distribution.

The full geoprofile is shown in Figure 3a2a, with a close-up of the London area in Figure $3 b \underline{2 b}$. Profiles for the four weeks between January $20^{\text {th }}$ and February $16^{\text {th }} 1945$ - the period during which Masterman (1972) states that the mean point of impact (M.P.I.) moved eastward at a rate of around two miles per week - are shown in Figure $4 \underline{3}$.

\section{Mean and median points of impact, and London M.P.I}

Figure $5 \underline{4}$ shows the results of the mean point of impact, median point of impact, mean point of impact for strikes within London and the mean point of impact for the London cluster identified by the DPM, calculated daily for rolling windows of 14 days from the first strike to the last.

\section{Discussion}

Our results suggest that although the Germans were almost certainly deceived in exactly the way the Double Cross Committee intended, this had little or no impact on the 
precise locations where V-2 rockets struck London, largely because of the rockets' inaccuracy.

The evidence from this study suggests that the V-2 was accurate only within very broad limits. The fitted sigma value of $10 \mathrm{~km}$ suggests clusters in which $99 \%$ of impacts fall within an area with a diameter of $60 \mathrm{~km}$ - too large for the Double Cross Committee's deception to have any measurable effect. A cluster with radius $30 \mathrm{~km}$ centred on Tower Bridge would stretch all the way from Heathrow in the west to Tilbury in the east, and from close to Welwyn Garden City in the north to Godstone in the south, an area roughly comparable to the whole of the region bounded by the M25 today.(the motorway encircling almost all of Greater London) today. The claimed movement of the M.P.I. of two miles east per week in January-February 1945 is no greater than the random shifts in M.P.I. in other directions across the whole bombardment.

Historical evidence also supports this view of the precision with which the rockets could be targeted. The first two rockets to strike London - 16 seconds apart, and presumably aimed at the same target - landed 16 miles $(25 \mathrm{~km})$ apart. Similarly, when the Germans attempted to use V-2 rockets against the Ludendorff Bridge at the Battle of Remagen (the V-2's first use against a tactical target), although most strikes were clustered within a few kilometres of the target, one rocket missed the bridge by less than a kilometre, but another struck Cologne, $64 \mathrm{~km}$ away (v2rocket.com,/start/deployment/v2s-on-remagen.html, retrieved 1 November 2018). Churchill himself stated that "The average error of both of these weapons [the V-1 and V-2] was over ten miles' (Ordway and Sharpe 1982). Clearly, this error swamps - for example - differences between targets within central London such as Tower Bridge or $\underline{\text { Southwark Fire Station, }(<2 \mathrm{~km} \text { apart). Note that although other targets included }}$ 


\section{Norwich, approximately $180 \mathrm{~km}$ away, as well as Southend and Canvey Island}

(V2Rocket.com), in our analysis the DPM model assigns these strikes to separate

$\underline{\text { clusters which do not affect our estimate of the cluster centred on London. Interestingly, }}$ $\underline{\text { recent research suggests that the M.P.I. of V-1 strikes was within } 3.5 \mathrm{~km} \text { of the centroid }}$ of the County of London (Evans and Delaney 2018), pointing out that high-resolution $\underline{\text { accuracy may be relatively unimportant when missiles with low accuracy are aimed at }}$ $\underline{\text { large targets such as cities. }}$

Although the mean point of impact does indeed move eastwards by considerable distances over the course of the analysis, this is largely a consequence of including much more distant strikes in the analysis. Restricting the analysis to the strikes allocated by the DPM to London shows movement on a much smaller spatial scale, but again there is no clear move eastwards. The same is true if we consider the M.P.I. for those strikes within London.

Attempts to understand spatial patterns of bombardment predate the V-2. Clarke (1946) examined the locations of V-1 impacts in south-east London (not V-2 impacts, as is sometimes mistakenly claimed) and showed that the data exhibited an excellent fit to a Poisson distribution, suggesting that the bombs did not cluster more than expected. This is perhaps surprising, since a Poisson distribution would be expected only if the chances of strikes were equal across the whole area, which is unlikely if the bombs were aimed at a particular target-; see Evans and Delaney (2018) for a more recent analysis. Interestingly, our analysis suggested a significant departure from the pattern expected under a Poisson distribution, as would be expected if the actual pattern forms a bivariate normal distribution around a central point (as the DPM assumes).

Perhaps the most striking contrast is between the extent to which the Double Cross Committee's deception succeeded, and the lack of a measurable effect. A large 
factor in the success of the deception's effect was due to MI5's success in dealing with German agents in UK, but this was aided by the lack of German photographic reconnaissance of London, although this was not known to the Double Cross Committee at the time. In fact, there was no German photographic reconnaissance of London between January $10^{\text {th }} 1941$ and September $10^{\text {th }} 1944$, largely because of the Fighter Command's efficiency in intercepting attempts (Jones 1978), so the only information available to the Germans came via the compromised agents.

\section{$\underline{\text { 5. Conclusions }}$}

Overall, our study finds no support for the idea that the Double Cross's deception had any practical effect on the locations of V-2 strikes in London. Across the whole bombardment, the brunt of the strikes was borne by the area around Ilford. The most charitable conclusion that can be drawn is that perhaps the deception operated successfully from the first V-2 impact to the last. This is not entirely implausible, given that we know the origins of the deception predate the V-2 and that substantially the same approach was used with the V-1. It does, however, contradictHowever, we believe this is unlikely, contradicting as it does both Masterman's view that the deception's effect applied principally to the period from mid-January 1945 to mid-February the same year (Masterman 1972).), and Evans and Delaney (2018)'s finding that deceptions $\underline{\text { undertaken by British Intelligence did not significantly alter the geography of V-1 }}$ impacts in London. Dornberger, who led the V-1 and V-2 development programmes and worked closely with Werner von Braun, stated that most intelligence came too late to be useful to correct aim (Dornberger 1954). According to Dornberger, the V-2 was not as effective as it should have been because it was deployed when it was not yet fully 
developed as a result of repeated delays due to bureaucratic and budgetary issues (Dornberger 1954).

It is hard to view the $\mathrm{V}$-weapon programme as a success, except perhaps in propaganda terms. Hitler's view was that the programme saved men and aircraft, but even if all 25,000 V-1 and V-2s had impacted at or near their target they would have delivered only 25,000 tons of explosive. This figure can be compared to 36,000 tons of explosive dropped on V-weapon launch sites in the six months leading up to D-Day. Certainly some of the Nazi hierarchy took thisOn the other hand, Evans and Delaney (2018) show how even relatively inaccurate missile systems (such as the V-1) can be effective against large targets such as cities, and it is undeniable that the vengeance weapons caused considerable alarm; indeed, the British government was sufficiently concerned about this to disguise the first V-2 impacts as gas explosions (Williams 2013). Certainly, though, some of the Nazi hierarchy took a more negative view: for example, Speer claimed in 1945 that 'from the point of view of their technical production the rockets were a very expensive affair for us, and their effect compared to the cost of their output was negligible'. In fact, at \$3 billion, the V-weapon programme cost a billion dollars more than the Manhattan Project (Ordway and Sharpe 1982).

More broadly, our results show for the first time how the DPM model of geographic profiling can be used to analyse the movement of clusters over time, an issue likely to be applicable in other areas; for example, modelling the spread of an invasive species over time, or changing patterns of disease transmission.

T.H. Huxley famously stated that the great tragedy of science was the slaying of a beautiful theory by an ugly fact (Huxley 1894). The coupling of spatial data from bombs that overshot with the temporal data from bombs that fell short was a beautiful and elegant idea, and a simple analysis of mean point of impact seems to support the 
claim that it was highly effective. Sadly, the ugly fact of a more sophisticated analysis appears to kill it. 


\section{FIGURE LEGENDS}

Figure 1. After-effects of a V-2 strike on Hughes Mansions, Vallance Road, London at 7.21 a.m. on March 27th 1945 , that killed 134 people. C IWM (HU 88803).

Figure 2. A captured German map showing impacts of $V$-1s on London from information by German agents (dark circles) and as indicated by radio transmitters in a subset of missiles (white circles). Copyright Penguin Books.

Figure 3.Geoprofiles based on all V-2 impacts (a), with a close up of the peak nearest central London (b). Black circles show impact sites. The red cross marks the location of Trafalgar Square in the centre of London.

Figure $4 \underline{3}$. Week-by-week geoprofiles showing the London peak for the four crucial weeks between January $20^{\text {th }}$ and February $16^{\text {th }} 1945$, during which Masterman (1972) claimed that the mean point of impact moved eastwards by 2 miles a week. Black circles show points of impact. Again, the red cross marks the location of Trafalgar $\underline{\text { Square. }}$

Figure 5 . Daily rolling estimates of (a) mean point of impact; (b) median point of impact; (c) mean point of impact for strikes occurring within London; and (d) mean point of impact of strikes allocated by the DPM to the London cluster. In each case the earlier data are shown in red, and the later data in blue. 


\section{REFERENCES}

Andrew, C., 2012. The defence of the realm: the authorized history of MI5. London: Allen Lane.

Clarke, R. D., 1946. An application of the Poisson distribution. Journal of the Institute of Actuaries, 72, 481.

Crowdy, T-., 2011. Deceiving Hitler: double cross and deception in World War II. Oxford: Osprey Publishing.

Dornberger, W., 1954. V2. London: Hurst and Blackett.

Dungan, T.D., 2005. V-2: a combat history of the fist ballistic missile. Yardley, PA: Westholme Publishing.

Evans S.G. and Delaney K.B., 2018. The V1 (Flying Bomb) attack on London (19441945); the applied geography of early cruise missile accuracy. Applied Geography 99, 44-53.

Faulkner S.C., et al., 2016. Using geographic profiling to compare the value of sightings vs trap data in a biological invasion. Diversity and Distributions 23, 104-112.

Faulkner S.C., et al., 2018. A spatial approach to combatting wildlife crime. Conservation Biology 32, 685-983.

Geman S, and Geman D., 1984. Stochastic relaxation, Gibbs distributions, and the Bayesian restoration of images. IEEE Transactions on Pattern Analysis and Machine intelligence 6, 721-741.

Hauge, M.V. et al., 2016. Tagging Banksy: using geographic profiling to investigate a modern art mystery. Journal of Spatial Science 61, 185-190.

Huxley, T. H. 1894. Collected essays. Cambridge: Cambridge University Press. 
Johnson, D., 1982. V1-V2 Hitler's Vengeance on London: The Full Story of the Year Hitler's Guided Missiles Fell on London. New York NY: Stein and Day.

Jonasan, T. and Olsson, S., 2012. Agent TATE: The Wartime Story of Harry Williamson. Stroud: Amberley Publishing.

Jones. R.V., 1978. Most secret war. London: Hamish Hamilton.

Le Comber, S.C. and Stevenson, M.D., 2012. From Jack the Ripper to epidemiology and ecology. Trends in Ecology and Evolution 27, 307-308.

Le Comber, S.C., et al., 2011. Geographic profiling as a novel spatial tool for targeting infectious disease control. International Journal of Health Geographics, 10, 35.

Macintyre, B., 2012. Double Cross: The True Story of The D-Day Spies. London: Bloomsbury Publishing.

Masterman, J.C., 1972. The double cross system. London: Pimlico.

Ordway, F.I., and Sharpe, M.R., 1982. The rocket team. Cambridge, MA: MIT Press.

R Core Team, 2015. R: A language and environment for statistical computing. $\mathrm{R}$ Foundation for Statistical Computing, Vienna, Austria. URL https://www.Rproject.org/.

Rossmo, D.K., 2000. Geographic profiling. Boca Raton, FL: CRC Press.

Struebig, M.J., et al., 2018. Addressing human-tiger conflict using socio-ecological information on tolerance and risk. Nature Communications 9, 3455.

Verity R., et al., 2014. Spatial targeting of infectious disease control: indentifying multiple, unknown sources. Methods in Ecology and Evolution 5, 647-655.

\section{Williams A. 2013. Operation crossbow: the untold story of the search for Hitler's} weapons. London, UK: Preface Publishing. 


\section{TABLES}

Table 1. Number of cells with zero to four V-2 strikes for the London impacts.

\begin{tabular}{|c|c|c|}
\hline Number of strikes & Observed & Expected \\
\hline 0 & 591 & 572.63 \\
\hline 1 & 107 & 138.25 \\
\hline 2 & 26 & 16.69 \\
\hline 3 & 3 & 1.34 \\
\hline 4 & 2 & 0.08 \\
\hline
\end{tabular}




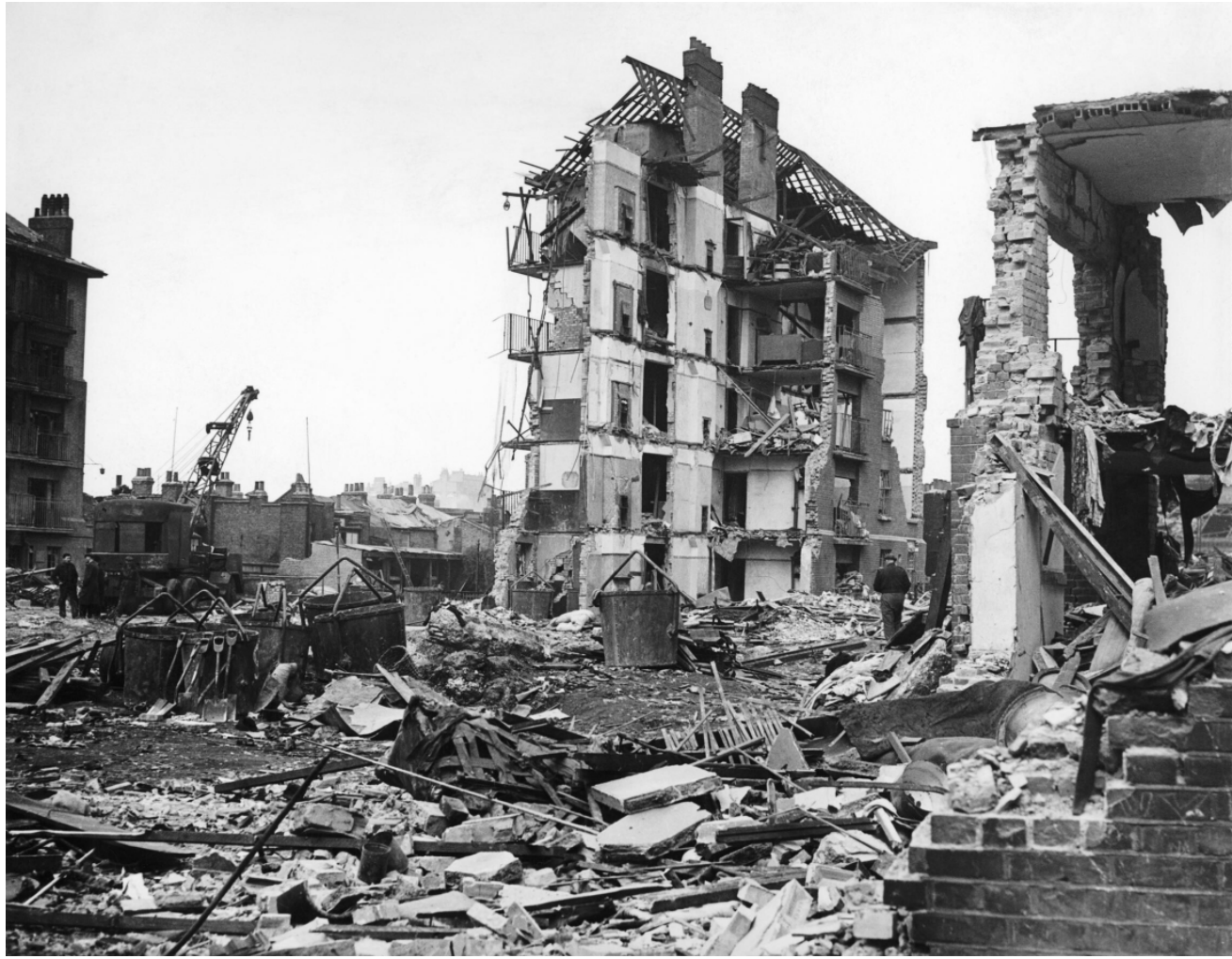

Figure 1. After-effects of a V-2 strike on Hughes Mansions, Vallance Road, London at 7.21 a.m. on March 27th, 1945, that killed 134 people. (C) IWM (HU 88803).

$803 \times 625 \mathrm{~mm}(72 \times 72$ DPI $)$ 

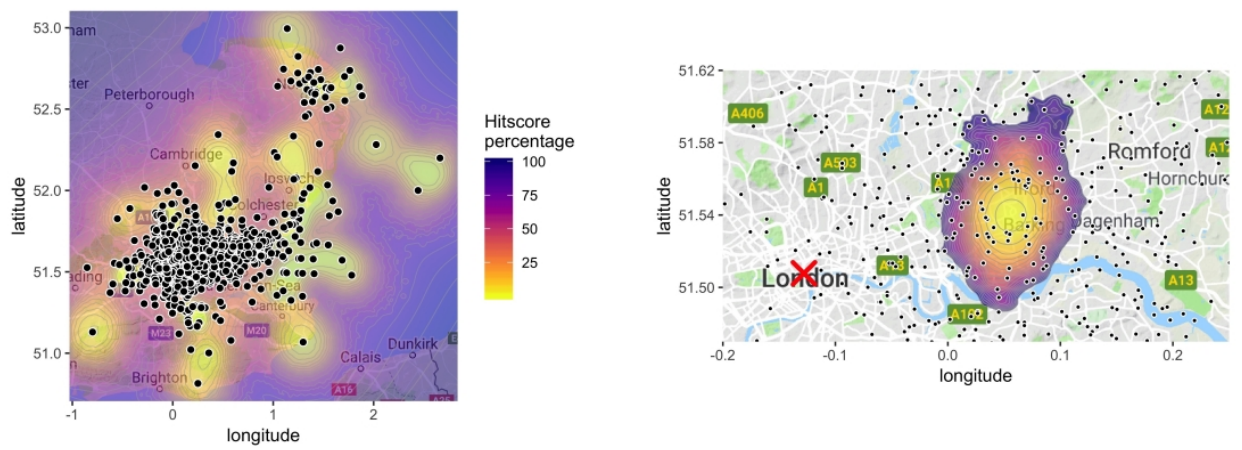

Figure 2. Geoprofiles based on all V-2 impacts (a), with a close up of the peak nearest central London (b). Black circles show impact sites. The red cross marks the location of Trafalgar Square in the centre of London.

$1948 \times 812 \mathrm{~mm}(72 \times 72$ DPI $)$ 

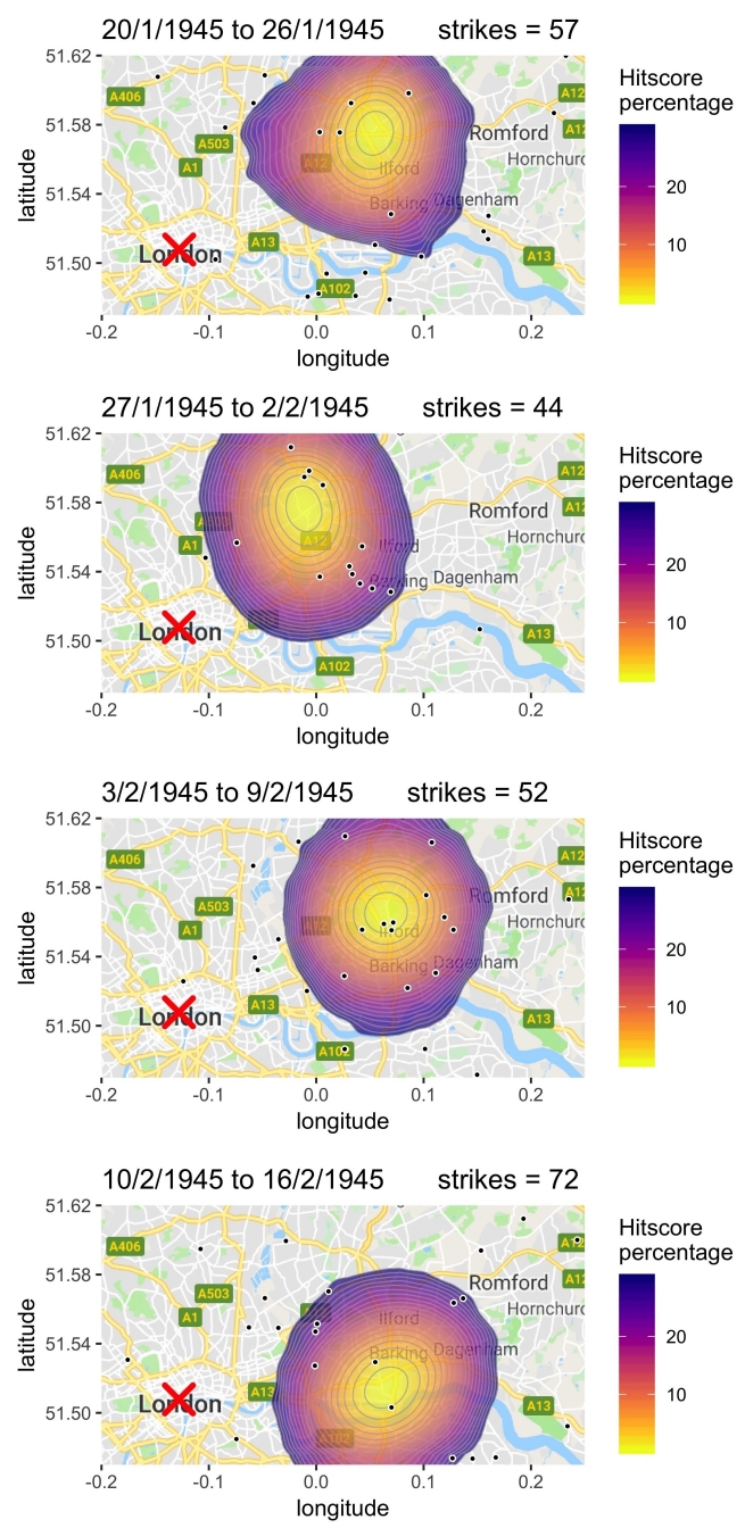

Figure 3. Week-by-week geoprofiles showing the London peak for the four crucial weeks between January 20th and February 16th 1945, during which Masterman (1972) claimed that the mean point of impact moved eastwards by 2 miles a week. Black circles show points of impact. Again, the red cross marks the location of Trafalgar Square.

$876 \times 1836 \mathrm{~mm}(72 \times 72$ DPI $)$ 

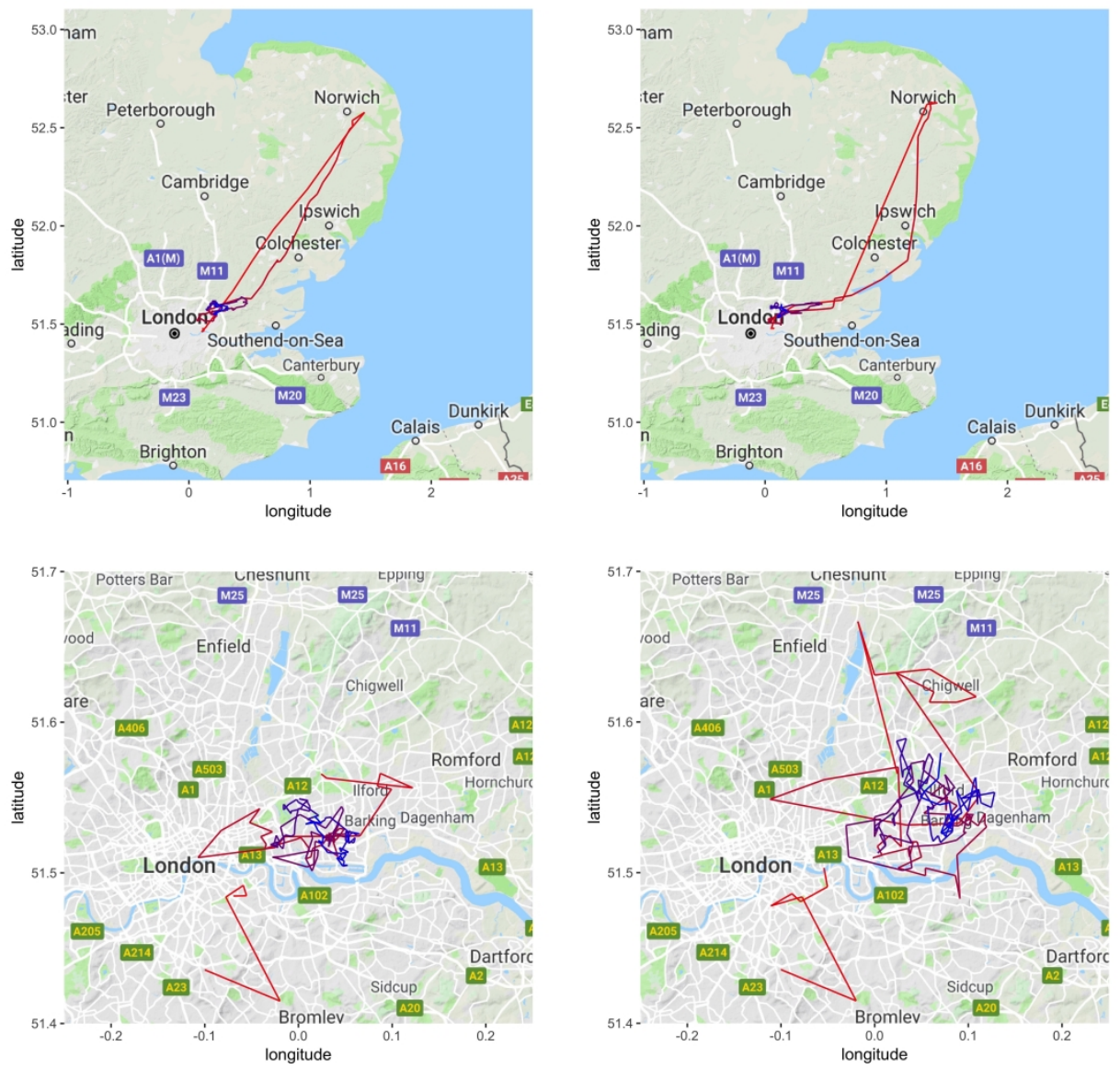

Figure 4. Daily rolling estimates of (a) mean point of impact; (b) median point of impact; (c) mean point of impact for strikes occurring within London; and (d) mean point of impact of strikes allocated by the DPM to the London cluster. In each case the earlier data are shown in red, and the later data in blue.

$1966 \times 1810 \mathrm{~mm}(72 \times 72 \mathrm{DPI})$ 